\title{
The Role of Interfacial Adhesion in Polymer Composites Engineered from Lignocellulosic Agricultural Waste
}

\author{
Dávid Kun ${ }^{1,2}$, Zoltán Kárpáti ${ }^{1,2}$, Erika Fekete ${ }^{1,2}$ and János Móczó ${ }^{1,2, *(\mathbb{D}}$ \\ 1 Laboratory of Plastics and Rubber Technology, Department of Physical Chemistry and Materials Science, \\ Budapest University of Technology and Economics, P.O. Box 91, H-1521 Budapest, Hungary; \\ kun.david@mail.bme.hu (D.K.); karpatizol@gmail.com (Z.K.); bodine.fekete.erika@vbk.bme.hu (E.F.) \\ 2 Institute of Materials and Environmental Chemistry, Research Centre for Natural Sciences, Eötvös Lóránd \\ Research Network, P.O. Box 286, H-1519 Budapest, Hungary \\ * Correspondence: jmoczo@edu.bme.hu; Tel.: +36-1-382-6569; Fax: +36-1-463-3474
}

check for updates

Citation: Kun, D.; Kárpáti, Z.; Fekete, E.; Móczó, J. The Role of Interfacial Adhesion in Polymer Composites Engineered from Lignocellulosic Agricultural Waste. Polymers 2021, 13, 3099. https:// doi.org/10.3390/polym13183099

Academic Editor: Dimitrios Bikiaris

Received: 30 June 2021

Accepted: 10 September 2021

Published: 14 September 2021

Publisher's Note: MDPI stays neutral with regard to jurisdictional claims in published maps and institutional affiliations.

Copyright: (c) 2021 by the authors. Licensee MDPI, Basel, Switzerland. This article is an open access article distributed under the terms and conditions of the Creative Commons Attribution (CC BY) license (https:// creativecommons.org/licenses/by/ $4.0 /)$.

\begin{abstract}
This paper presents a comprehensive study about the application of a lignocellulosic agricultural waste, sunflower husk in different polymer composites. Two types of milled sunflower husk with different geometrical factors were incorporated into polypropylene, low-density and high-density polyethylene, polystyrene (PS), glycol-modified polyethylene terephthalate (PETG) and polylactic acid (PLA). The filler content of the composites varied between 0 and $60 \mathrm{vol} \%$. The components were homogenized in an internal mixer and plates were compression molded for testing. The Lewis-Nielsen model was fitted to the moduli of each composite series, and it was found that the physical contact of the filler particles is a limiting factor of composite modulus. Interfacial interactions were estimated from two independent approaches. Firstly, the extent of reinforcement was determined from the composition dependence of tensile strength. Secondly, the reversible work of adhesion was calculated from the surface energies of the components. As only weak van der Waals interactions develop in the interphase of polyolefins and sunflower husk particles, adhesion is weak in their composites resulting in poor reinforcement. Interfacial adhesion enhanced by specific interactions in the interphase, such as $\pi$ electron interactions for PS, hydrogen bonds for PLA, and both for PETG based composites.
\end{abstract}

Keywords: particle-reinforcement; adhesion; stress transfer; mechanical testing

\section{Introduction}

In recent years, sustainability has become a principle in many areas, including polymer science and engineering. As a result, more and more effort has been made to decrease the amount of fossil-based polymers and replace them with renewable, natural ones. However, these intentions are surrounded by a number of challenges since the processability and properties of natural polymers are inferior to those of petroleum-based plastics. Several approaches can be followed to eliminate these drawbacks, among which the preparation of polymer composites and blends is a relatively simple, efficient and economical option.

In the literature, numerous papers can be found about the utilization of bio-based as well as renewable, natural polymers in blends and composites. Bio-polyethylene [1,2], starch [3-6], protein [7,8] and lignin [9-14] have been used as a matrix or dispersed component of blends, while cellulose [15-18], chitin [5,19] and lignocellulose [4,9,20-24] have been applied as a reinforcement in composites. In addition, the advantageous properties of bio-based polymers and natural fibers were combined in their composites in several cases $[1,18,24]$. Among lignocellulosic fillers, many types of harvest wastes have been studied as well, including rice hulls [25], wheat straw [26], sugarcane bagasse [27], corn cobs [28], sunflower stalks [29], etc.

Sunflower husk is also a lignocellulosic waste material, and similarly to the above mentioned harvest wastes, it is available at low price and in large quantities. It consists of 
$34 \mathrm{wt} \%$ cellulose, $25 \mathrm{wt} \%$ lignin, $27 \mathrm{wt} \%$ hemicellulose and $13 \mathrm{wt} \%$ extractives [30]. Due to its considerable heat of combustion, it is used mostly as fuel to provide heat for the sunflower oil extraction process [31]. This means that the utilization of sunflower husk in composites could involve both economic and environmental advantages; however, this latter is somewhat reduced by the difficult handling of composites when they also become waste. In the paper of Angellier-Coussy et al. [32], several approaches are discussed for the waste management of lignocellulosic composites. Among them, a promising recycling procedure is shown by Grozdanov et al. [33]. The first step was the incorporation of rice husks and kenaf fibers into PLA, which was followed by the milling of these biocomposites. Eventually, the milled material was successfully applied as reinforcement in polyester resin.

Polymer/lignocellulose composites are used as structural materials in packaging [34,35], automotive industry [35-37], building and construction [35,38-40] and furniture production $[35,38]$. Polymer/sunflower husk composites could be applied for the same purposes. Nevertheless, only a few articles have been published about the application of sunflower husk as filler in polymer composites [41-44].

In the work of Sui et al. [41], polypropylene (PP) was filled with $5 \mathrm{wt} \%$ sunflower hull sanding dust (SHSD). According to the images taken by scanning electron microscope (SEM), the particles of SHSD were slightly fibrous with sizes in the range of 1-10 $\mu \mathrm{m}$. Mechanical testing showed that the flexural modulus and strength of the composite were higher than those of the neat PP. The reinforcing effect of SHDS can be related probably to its slightly fibrous structure since the adhesion is poor between polyolefins and lignocelluloses due to their low surface energy [45]. The role of structure was also shown by Salasinska and Ryszkowska [42]. In their work, composites were prepared through the combination of finely ground sunflower husk and high-density polyethylene (HDPE) in a relatively wide composition range, from 5 to $30 \mathrm{wt} \%$ filler content. The modulus increased monotonically with increasing sunflower husk content, while tensile strength had a maximum at $15 \mathrm{wt} \%$ filler loading. Improved strength implies adequate stress transfer between the components which resulted from the high aspect ratio and the fine dispersion of the sunflower husk particles.

Marhoon [43] used sunflower husk as reinforcement in polyurethane composites. Sunflower husk was milled, sieved into different size fractions $(<53,<75$ and $<106 \mu \mathrm{m})$ and added to flexible polyurethane until $10 \mathrm{wt} \%$ in $2 \mathrm{wt} \%$ steps. The modulus of elasticity and tensile strength increased with increasing filler content. Additionally, the gradient of the tendencies increased with decreasing particle size since smaller filler particles created larger contact surface area with the matrix polymer, which provided better stress transfer between the components. In another work, Barczewski et al. [44] prepared epoxy-based composites containing 15-35 wt\% sunflower hull with an average particle size of $110.6 \mu \mathrm{m}$ and an aspect ratio of 3.04. Tensile and flexural strength deteriorated upon the addition of sunflower husk, which were explained by the occurrence of voids during sample preparation as well as by the release of fat residues from the filler during the exothermic cross-linking process resulting in the plasticization of the composite.

The properties of polymer composites are affected by component characteristics, composition, structure and interfacial interactions. In many papers about composites, the primary focus is put on studying the role of structure while quite few articles discuss the role of interactions, and even fewer do that with quantitative analyses. In our previous paper [46], we investigated the role of interfacial adhesion in the composites of polyolefins and milled sunflower husk. At the interface between the components, interactions were modified by maleic-anhydride-grafted polyolefin coupling agents. The results unambiguously proved that coupling improved interfacial adhesion, which changed the dominant micromechanical deformation process from debonding to particle fracture. As a result, the strength of the composites increased considerably; however, their elongation-at-break values remained low, which may hinder application in practice. 
For the engineering of interfacial interactions in composites, another simple approach is actually the selection of a matrix polymer with adequate surface properties. Although there are numerous articles about lignocellulose reinforced composites, in most cases only one or two types of polymers are used as a matrix component. This means that quantitative analysis is limited and general conclusions about the role of interactions can hardly be drawn. Therefore, we selected several thermoplastic polymers having different moduli, different surface energies, and that are capable of forming different intermolecular interactions with the applied filler. We filled these polymers with milled sunflower husk in a wide composition range to study quantitatively the effect of interfacial adhesion on the mechanical properties of the composites. In the experiments, we used two types of sunflower husk filler with different size and aspect ratio to investigate the possible role of structure, as well.

\section{Experimental}

\subsection{Materials}

Six commercially available thermoplastic polymer grades were used as matrix, namely polypropylene (PP), low-density polyethylene (LDPE), high-density polyethylene (HDPE), polystyrene (PS), glycol-modified polyethylene terephthalate (PETG) and polylactic acid (PLA). All of these polymers were used in the form of pellets with 1-2 mm diameter. The type, source and the most important properties of the polymers used in this study are provided in Table 1. Two types of milled sunflower husk were applied as filler in the composites, and both of them were supplied by Bunge (Chesterfield, Missouri, USA). The SunPro Fiber (SPF) and SunPro 20 (SP20) grades are already milled and they contain slightly fibrous particles. The average particle length of SPF is $2600 \mu \mathrm{m}$, the aspect ratio is 3.3 , and the density is $1.42 \mathrm{~g} / \mathrm{cm}^{3}$, while these characteristics of SP20 are $1100 \mu \mathrm{m}, 2.8$, and $1.44 \mathrm{~g} / \mathrm{cm}^{3}$.

Table 1. The most important properties of the matrix polymers used in the experiments.

\begin{tabular}{|c|c|c|c|c|c|}
\hline Polymer & Trade Name & Producer & Density $\left(\mathrm{g} / \mathrm{cm}^{3}\right)$ & $\begin{array}{c}\text { MFR }^{a} \\
(g / 10 \text { min })\end{array}$ & $\begin{array}{c}\text { Temp. }\left({ }^{\circ} \mathrm{C}\right) \\
\text { and Load }(\mathrm{kg}) \text { of MFR }\end{array}$ \\
\hline $\mathrm{PP}$ & H $649 \mathrm{FH}$ & \multirow{3}{*}{$\begin{array}{c}\text { MOL Group } \\
\text { (Budapest, Hungary) }\end{array}$} & 0.90 & 2.5 & $230,2.16$ \\
\hline LDPE & FA-244-51 & & 0.92 & 0.28 & $190,2.16$ \\
\hline HDPE & Tipelin 7100S & & 0.95 & 0.25 & $190,5.00$ \\
\hline PS & Styron 686 E & $\begin{array}{c}\text { Americas Styrenics } \\
\text { (The Woodlands, TX, USA) }\end{array}$ & 1.05 & 2.5 & $200,5.00$ \\
\hline PETG & Ecozen SE & $\begin{array}{c}\text { SK Chemicals } \\
\text { (Seongnam, Korea) }\end{array}$ & 1.27 & 10.9 & $250,2.16$ \\
\hline PLA & Ingeo 4032 & $\begin{array}{c}\text { NatureWorks } \\
\text { (Minnetonka, MN, USA) }\end{array}$ & 1.24 & 3.9 & $190,2.16$ \\
\hline
\end{tabular}

${ }^{\text {a }}$ Melt flow rate.

\subsection{Sample Preparation}

Prior to sample preparation, sunflower husk fillers were dried in the air at $105{ }^{\circ} \mathrm{C}$ for $12 \mathrm{~h}$ in a ventilated oven, while PETG and PLA were kept at 200 mbar air pressure and $105^{\circ} \mathrm{C}$ for $4 \mathrm{~h}$ in a vacuum oven to remove their humidity content. The components were homogenized in a Brabender W 50 EHT internal mixer at $42 \mathrm{~cm}^{3}$ charge volume and $50 \mathrm{rpm}$. First, the polymer was melted within 1-2 $\mathrm{min}$, then the filler was added and mixing was carried out for additional $10 \mathrm{~min}$. Set temperature was $190^{\circ} \mathrm{C}$ for the PS and PETG composites, $180^{\circ} \mathrm{C}$ for the PP and PLA ones, as well as $160^{\circ} \mathrm{C}$ for the LDPE and HDPE ones. The filler content of the composites increased from 0 to $30 \mathrm{vol} \%$ in $5 \mathrm{vol} \%$ steps, and from 30 to $60 \mathrm{vol} \%$ in $10 \mathrm{vol} \%$ steps.

Immediately after mixing, 1-mm-thick plates were compression molded from the still plastic materials using a Fontijne SRA 100 machine. The temperature of compression 
molding was set at the same value as that of the internal mixer for each material. After the plates had been stored at room temperature and 50\% relative humidity for one week, 5 tensile bars (type 1A ISO) were machined from each composite for further testing.

\subsection{Characterization}

The surface tension of unmilled sunflower husk and the polymers applied was determined by static contact angle measurements using the OWRK method [47-50]. Diiodomethane was used for the determination of the dispersion component of surface tension, while water, ethylene glycol and formamide were applied for the estimation of the polar component. The contact angle of $20 \mu \mathrm{L}$ liquid droplets was measured at $23^{\circ} \mathrm{C}$ and $50 \%$ relative humidity with a Ramé-Hart goniometer.

Mechanical properties (modulus, strength and elongation-at-break) were determined by tensile testing using an Instron 5566 universal testing machine. Gauge length was $115 \mathrm{~mm}$ and the cross-head speed was set at $5 \mathrm{~mm} / \mathrm{min}$. The structure of the composites was studied by digital optical microscopy (DOM) using a Keyence VHX 5000 apparatus. Micrographs were recorded on the compressed surface of the plates.

\subsection{Statistical Analysis}

The modulus of the sunflower husk particles was estimated by applying the model of Lewis and Nielsen [51]. The model was fitted to the moduli of the composites by nonlinear regression using the Generalized Reduced Gradient Nonlinear algorithm. The iteration steps were done by the Solver add-in of Microsoft Excel (Version 2016, Microsoft, Redmond, WA, USA).

Analysis of covariance (ANCOVA) was performed to determine the statistical significance of structure and interfacial adhesion in the reinforcing effect of sunflower husk. The level of significance was set at 0.05 , thus a factor was considered to be significant in case its $p$-value was smaller than 0.05 . Calculations were carried out by means of Statistica software (Version 13.3, TIBCO Software, Palo Alto, CA, USA).

\section{Results and Discussion}

The results are presented and discussed in several sections. Firstly, the factors limiting the modulus of the composites are studied. Secondly, the composition dependence of strength and elongation-at-break is presented, which expresses the performance of the composites at failure. Thirdly, the reinforcing effect of sunflower husk is analyzed quantitatively, and eventually, it is related to interfacial adhesion and structure.

\subsection{The Limiting Factors of Modulus}

A number of applications are subjected to static loading; thus, they must be engineered with adequate stiffness to maintain their dimensions. In many cases, the modulus of neat polymers is too low, thus their particulate filled composites are used instead. Many papers have shown that the incorporation of lignocellulosic fillers can enhance the modulus of polymers [4,9,20-24]; however, the limiting factors are rarely discussed. In Figure 1, the modulus of the composites is plotted as a function of sunflower husk content. Young's modulus increases with increasing filler content for all the composite series studied since the lignocellulosic particles of sunflower husk have a higher modulus than the polymer matrices. For a better understanding of the tendencies, the semiempirical model of Lewis and Nielsen [38] was fitted to the measured moduli by nonlinear regression. This model can be expressed by the following equations.

$$
\begin{gathered}
E=E_{m} \frac{1+A B \varphi}{1-B_{E} \psi \varphi} \\
A=\frac{7-5 v_{m}}{8-10 v_{m}}
\end{gathered}
$$




$$
\begin{gathered}
B_{E}=\frac{\frac{E_{f}}{E_{m}}-1}{\frac{E_{f}}{E_{m}}+A} \\
\psi=1+\frac{1-\varphi_{\max }}{\varphi_{\max }^{2}} \varphi
\end{gathered}
$$

where $E, E_{m}$ and $E_{f}$ are the Young's moduli $\{\mathrm{GPa}\}$ of the composite, the matrix and the filler, respectively, $v_{m}$ is the Poisson's ratio $\{\mathrm{mm} / \mathrm{mm}\}$ of the matrix, $\varphi$ is the filler content $\left\{\mathrm{cm}^{3} / \mathrm{cm}^{3}\right\}$, and $\varphi_{\max }$ is the maximum packing fraction $\left\{\mathrm{cm}^{3} / \mathrm{cm}^{3}\right\}$ of the filler. The two parameters, $A$ and $\Psi$, are related to the structure of the composite; however, they are not very well defined [52]. Parameter $A$ can be related to filler anisotropy, through the relation $A=k_{E}-1$, where $k_{E}$ is the Einstein's coefficient, but the relation has not been thoroughly investigated and verified yet. Parameter $\Psi$ is the function of the maximum packing fraction, thus it is related to anisotropy, but it is affected also by the formation of an interphase. Despite these uncertainties, the Lewis-Nielsen model is quite frequently used to predict the modulus of particulate filled composites [52]. In order to estimate $\varphi_{\max }$, the sunflower husk particles were assumed to be ellipsoids having aspect ratios between 2.8 and 3.3, and being in maximally random jammed state. Based on the simulations of Donev et al. [53], the maximum packing density is approximately 0.67 for such particles, therefore we used this value as $\varphi_{\max }$.

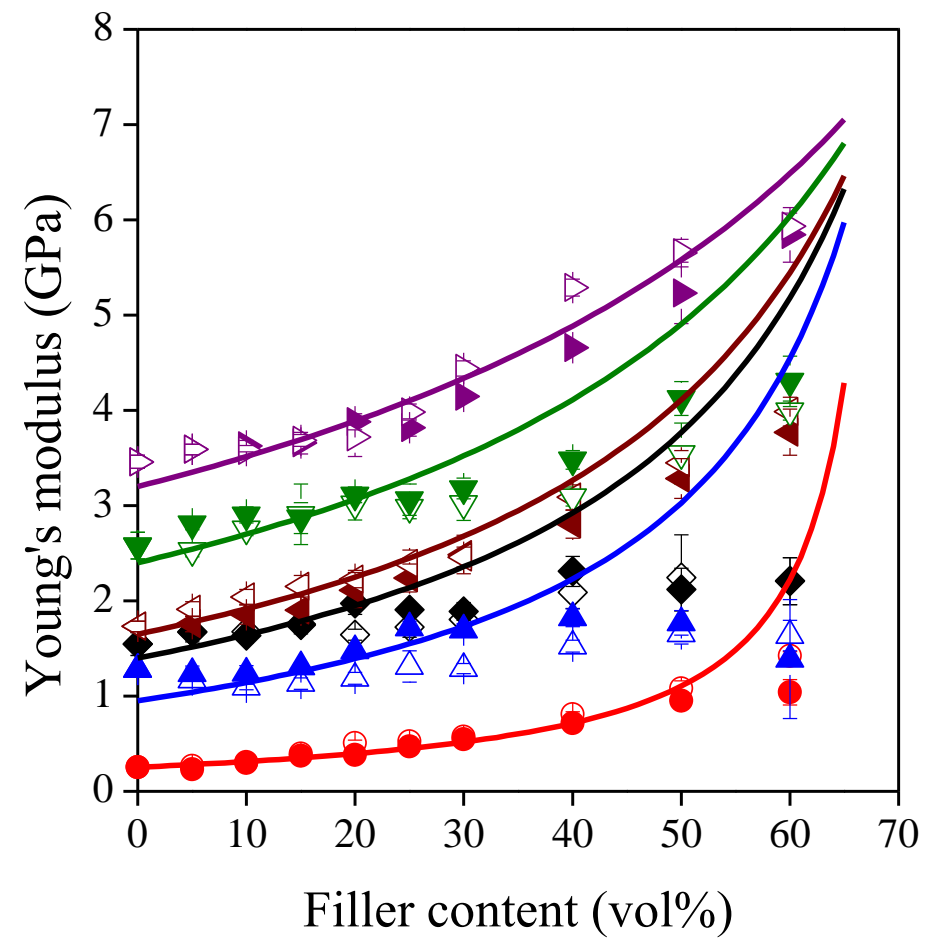

Figure 1. Effect of filler content on the stiffness of the composites. Symbols: $(\diamond)$ PP; $(\bigcirc)$ LDPE; $(\triangle)$ HDPE; $(\nabla)$ PS; $(\triangleleft)$ PETG; $(\triangleright)$ PLA; empty symbols: SP20; full symbols: SPF; Lewis-Nielsen model.

The average modulus of the filler particles was an output of the nonlinear regression, thus its value determined the fitted curves. When all moduli were involved in the nonlinear regression, the Lewis-Nielsen model did not fit adequately to the data. The deviation between the observed and fitted data was the highest at large filler contents, which indicates the appearance of a factor being neglected by the model. The validity range was determined by removing the observed moduli one by one from $60 \mathrm{vol} \%$ to lower filler contents, and then by re-fitting the model to the remained data. For both fillers, the results of the best fits are summarized in Table 2, while the goodness-of-fit is demonstrated by Figure 2 showing the estimated moduli plotted against the observed moduli from the validity interval. The modulus of the two filler types does not differ significantly from each other, therefore the 
Lewis-Nielsen model was re-fitted to the data of all the composite series studied, and the fitted curves were also placed in Figure 1. The common modulus of sunflower husk particles was found to be $7.50 \pm 0.71 \mathrm{GPa}$, which is close to the modulus of lignocellulosic filler materials with similar size, anisotropy and composition [54-56], but it is inferior compared to those with a more fibrous structure and higher cellulose content [56].

Table 2. Fitting results of the Lewis-Nielsen model [38].

\begin{tabular}{|c|c|c|c|c|c|c|c|c|}
\hline \multirow{2}{*}{ Filler } & \multicolumn{6}{|c|}{$\begin{array}{l}\text { Upper Composition Limit of Model Validity } \\
\text { (vol\% Filler Content) }\end{array}$} & \multirow{2}{*}{$\begin{array}{l}\text { Filler Modulus a } \\
\qquad(\mathrm{GPa})\end{array}$} & \multirow{2}{*}{$\mathbf{R}^{2 b}$} \\
\hline & PP & LDPE & HDPE & PS & PETG & PLA & & \\
\hline SP20 & 0.15 & 0.50 & 0.15 & 0.20 & 0.40 & 0.50 & $7.63 \pm 0.45$ & 0.8859 \\
\hline SPF & 0.20 & 0.40 & 0.30 & 0.25 & 0.30 & 0.40 & $7.45 \pm 0.69$ & 0.8519 \\
\hline
\end{tabular}

${ }^{\mathrm{a}}$ Error shows the $95 \%$ confidence interval; ${ }^{\mathrm{b}}$ coefficient of determination indicating the goodness of fit.

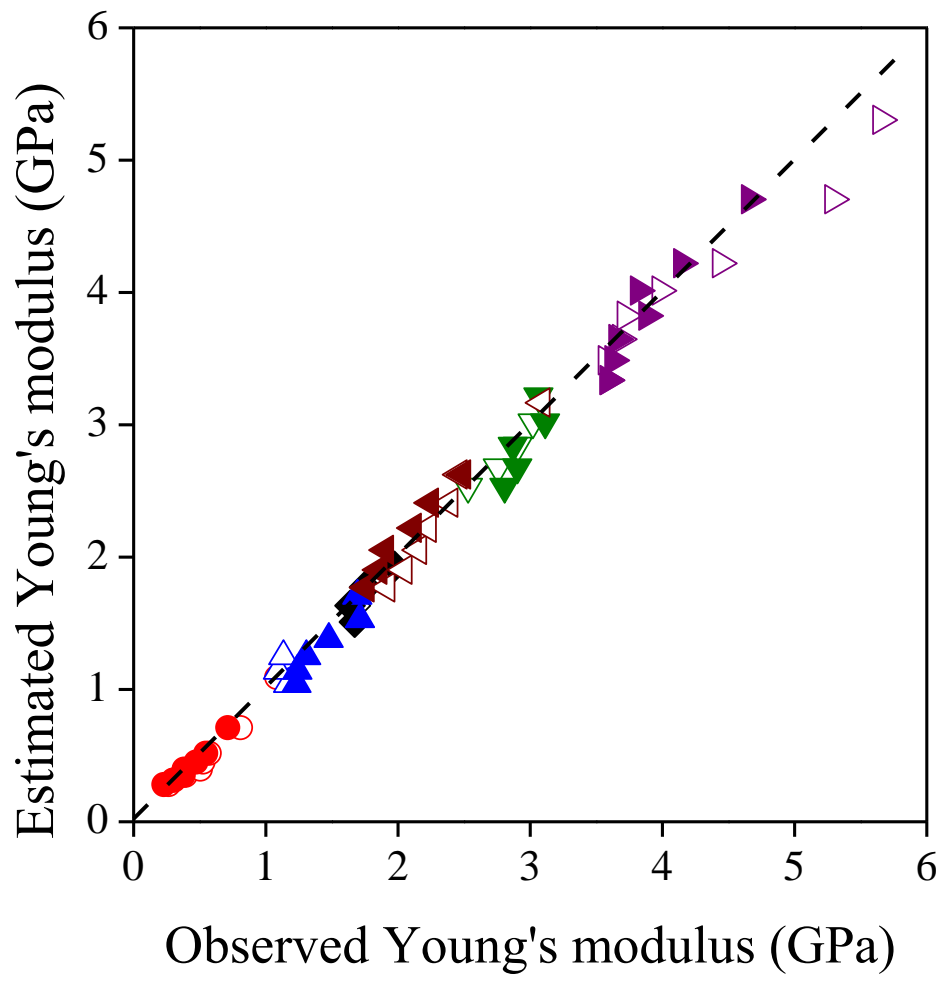

Figure 2. Estimated moduli as a function of observed moduli representing the goodness-of-fit for the Lewis-Nielsen model. Symbols: $(\diamond)$ PP; $(\bigcirc)$ LDPE; $(\triangle)$ HDPE; $(\nabla)$ PS; $(\triangleleft)$ PETG; $(\triangleright)$ PLA; empty symbols: SP20; full symbols: SPF.

The limited validity of the Lewis-Nielsen model can be attributed to the surface properties of the components. Firstly, we can assume poor interfacial adhesion between the milled sunflower husk and the polymers possessing low surface energy, such as poliolefins and PS, which could result in the debonding of matrix/filler interface around larger particles even at very small deformations where the modulus of the composites was determined [57,58]. Secondly, we can also assume that the wettability of the sunflower husk is poor, which results in the physical contact of their particles at higher filler contents as shown by the DOM images of Figure 3. Since these associations are held together only by weak interactions, they can be easily disrupted $[57,59]$. This effect can induce the formation of voids around the filler particles resulting in lower modulus than expected. 

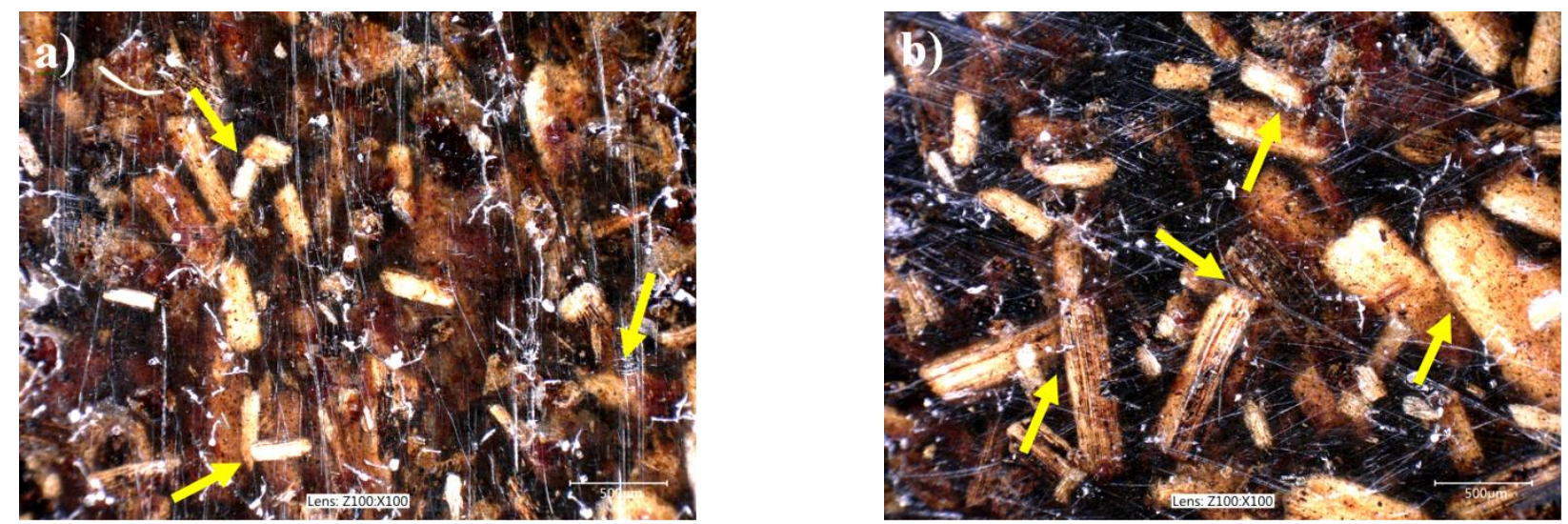

Figure 3. Physical contact between the sunflower husk particles in HDPE composites. Arrows show some physical contact points. The white scratches are the imprints of the steel mold. Filler content: 40 vol\%. (a) SP20; (b) SPF.

\subsection{Performance at Failure}

The practical relevance of a composite material is demonstrated not only by its modulus but also by the mechanical properties measured at failure, such as strength and deformation-at-break. In Figure 4, tensile strength is plotted against sunflower husk content. In all cases, strength decreases with increasing filler loading, but the gradient of the tendencies is quite different. On an absolute scale, the strength of PLA based composites decreases drastically, while that of LDPE and PS based ones changes slightly. The decrease of strength is often considered to be a consequence of weak interfacial adhesion between the matrix polymer and the filler. However, strength is affected not only by interfacial interactions but also by matrix [60] and filler properties [61], as well as by structure [62], thus a proper analysis of the tendencies requires the application of adequate models (see next section).

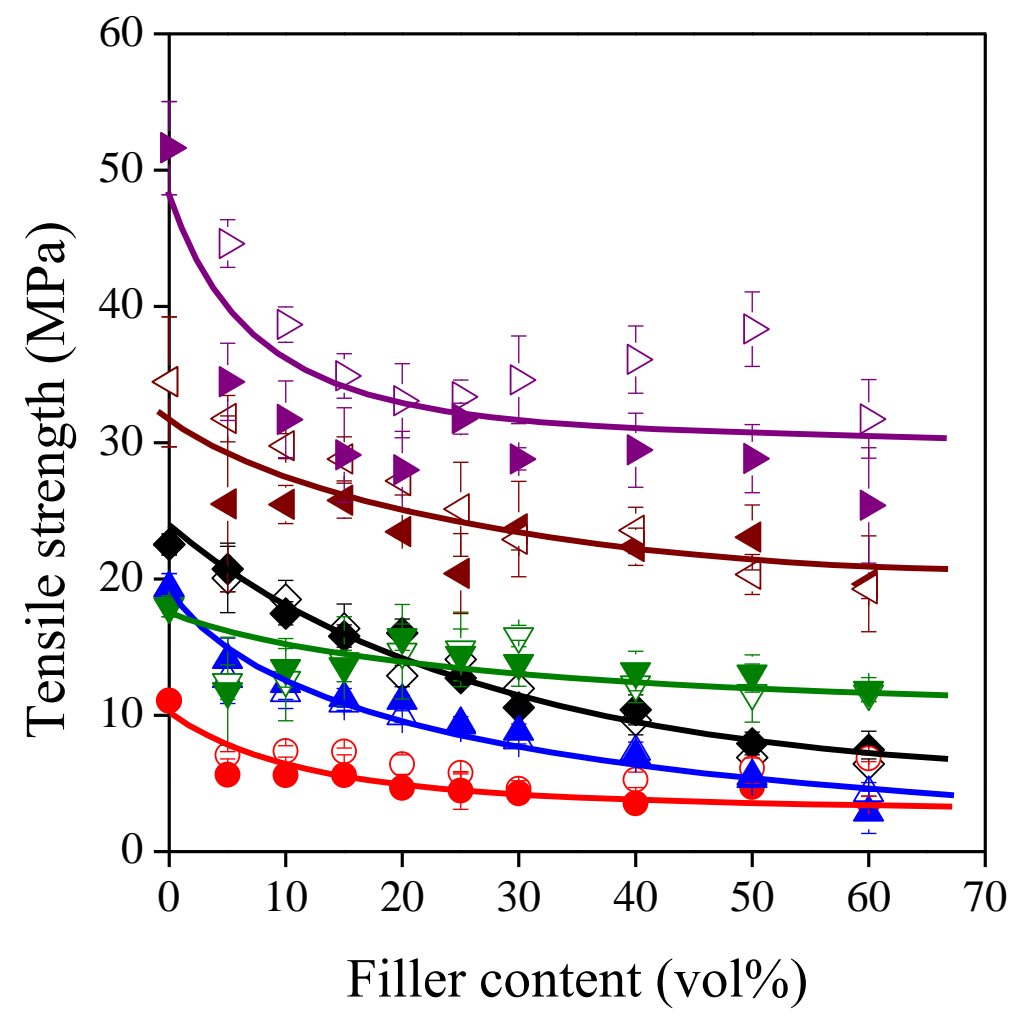

Figure 4. Effect of filler content on the strength of the composites. Symbols: $(\diamond) \mathrm{PP} ;(\bigcirc)$ LDPE; $(\triangle)$ HDPE; $(\nabla)$ PS; $(\triangleleft)$ PETG; $(\triangleright)$ PLA; empty symbols: SP20; full symbols: SPF. 
The brittleness of the composites studied is well demonstrated by their elongationat-break values which are presented as a function of sunflower husk content in Figure 5. Deformability is decreased significantly by the incorporation of the rigid filler particles results. The highest elongation-at-break values were measured for the polyolefin based composites, while the lowest values were determined for the PS based systems. This observation implies that the tendencies are mostly determined by the deformability of the matrix polymer, which is proved by Figure 6 showing the correlation between the elongation-at-break of the matrix polymer and that of the composites at $10 \mathrm{vol} \%$ and $40 \mathrm{vol} \%$ filler loading, respectively. The data are plotted on a logarithmic scale since they cover a range of 3-4 orders of magnitude.

\subsection{Reinforcing Effect of Filler}

As was mentioned earlier, the strength of a composite is affected by many factors including interfacial adhesion, matrix and filler properties, as well as structure [60-62]. The application of the model proposed by Pukánszky et al. [63] offers the possibility to study these factors quantitatively. This semi-empirical model is based on the Nicolais-Narkis model [64], but it uses an effective load-bearing cross-section of the matrix, as well as it takes into account the influence of interfacial interactions. The composition dependence of tensile strength is expressed by the following formula [63].

$$
\sigma_{\text {Tred }}=\sigma_{T} \frac{1+2.5 \varphi}{1-\varphi} \frac{1}{\lambda^{n}}=\sigma_{T m} \exp (B \varphi)
$$

where $\sigma_{\text {Tred }}$ is the reduced tensile strength $\{\mathrm{MPa}\}, \sigma_{T}$ and $\sigma_{T m}$ are the true tensile strength $\{\mathrm{MPa}\}$ of the composite and the matrix, respectively $\left(\sigma_{T}=\sigma \lambda\right.$ and $\lambda=L / L_{0}$, where $L$ is the ultimate and $L_{0}$ the initial gauge length $\{\mathrm{mm}\}$ of the specimen), $n$ is a parameter taking into account strain hardening \{dimensionless\}, $\varphi$ is the volume fraction $\left\{\mathrm{cm}^{3} / \mathrm{cm}^{3}\right\}$ of the filler, and $B$ is related to its relative load-bearing capacity \{dimensionless\}, i.e., to the extent of reinforcement. Parameter $B$ is determined by the size of the interface between the matrix and the filler and by the properties of the interphase [65]

$$
B=\left(1+A_{d} \rho_{d} \ell\right) \ln \left(\frac{\sigma_{i}}{\sigma_{T 0}}\right)
$$

where $A_{d}$ and $\rho_{d}$ are the specific surface area and density of the filler, while $\ell$ and $\sigma_{i}$ are the thickness of the interphase and its strength, respectively. Since the thickness of the interphase $(\ell)$ depends on the strength of interactions, parameter $B$ can provide information also about interfacial adhesion.

If we take the logarithm of the two sides of Equation (5), we receive the following linear form

$$
\ln \sigma_{\text {Tred }}=\ln \left(\sigma_{T} \frac{1+2.5 \varphi}{1-\varphi} \frac{1}{\lambda^{n}}\right)=\ln \sigma_{T m}+B \varphi
$$

where the dependent variable is the natural logarithm of reduced tensile strength, the independent variable is the volume fraction of the filler, the intercept is the natural logarithm of the matrix strength, and the slope is equal to parameter $B$. The reduced tensile strength of PP/SP20 and PETG/SP20 composite series is plotted this way with the fitted linear curves in Figure 7, while the fitting results are summarized in Table 3 for all the series studied. Based on the fitted $B$ values, two major groups can be distinguished. For the poliolefin based composites, parameter $B$ is quite small implying the presence of only weak van der Waals forces in the interphase. The other composites have higher $B$ values, which can originate from the formation of specific interactions in the interphase, such as $\pi$ electron interactions for PS [66-69], hydrogen bonds for PLA [70], and both for PETG based systems [66-70]. 


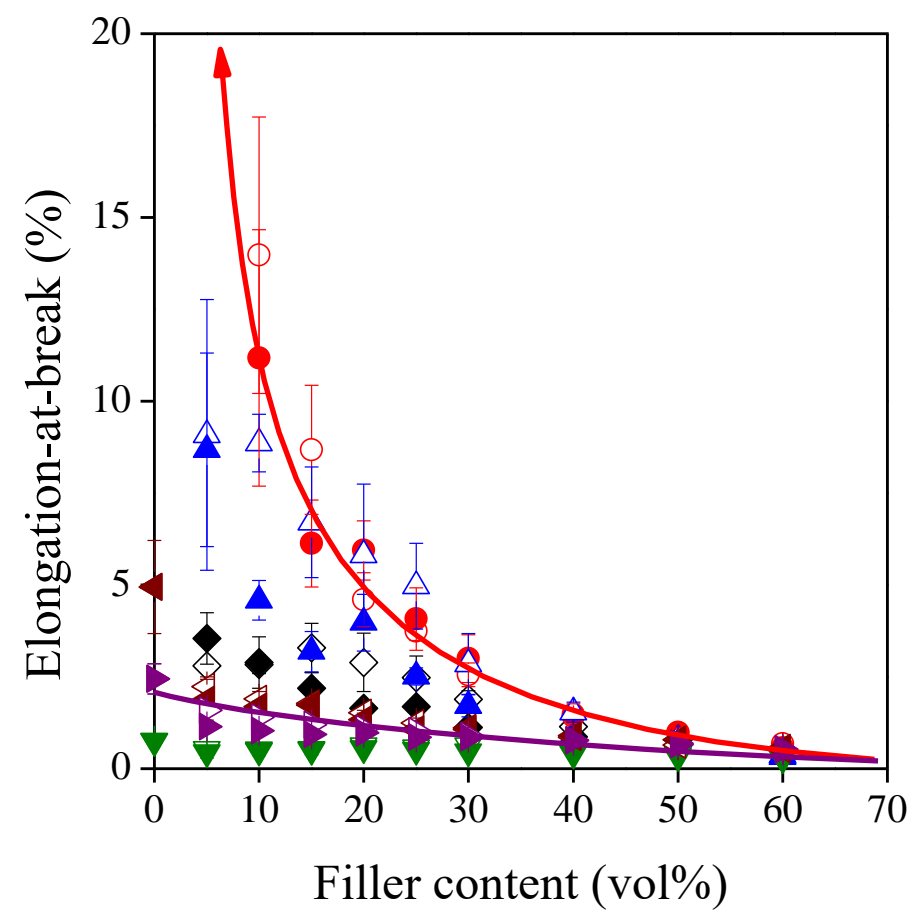

Figure 5. Effect of filler content on the brittleness of the composites. Symbols: $(\diamond)$ PP; $(\bigcirc)$ LDPE; $(\triangle)$ HDPE; $(\nabla)$ PS; $(\triangleleft)$ PETG; $(\triangleright)$ PLA; empty symbols: SP20; full symbols: SPF. One trend line represents the LDPE composites having the highest deformability, and the other one represents the much more rigid PLA composites.

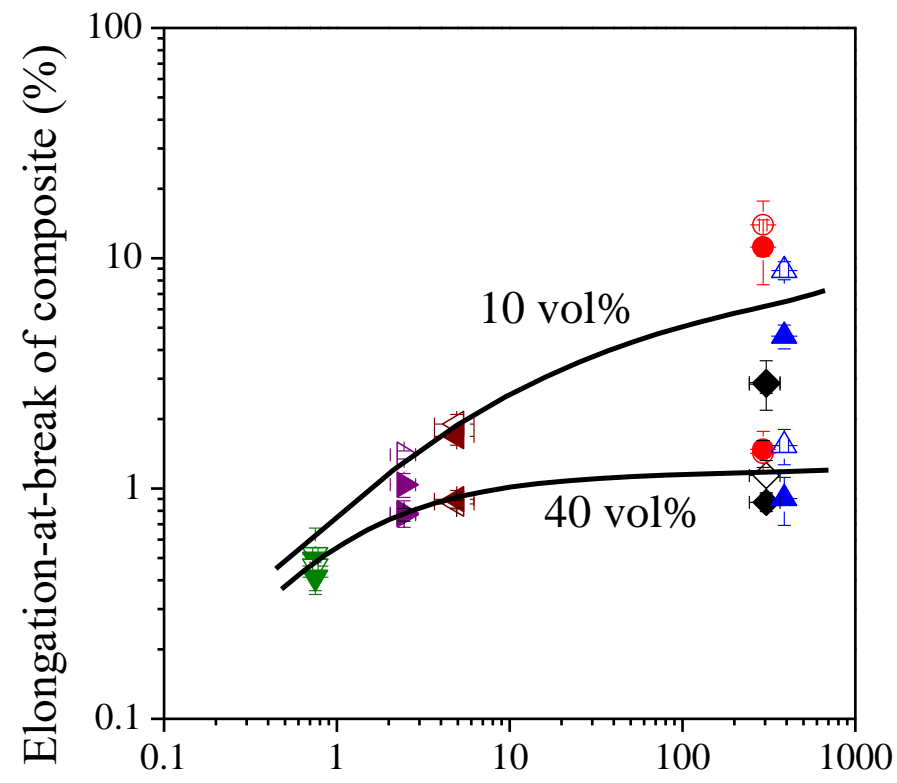

\section{Elongation-at-break of matrix polymer (\%)}

Figure 6. Correlation between the deformability of the matrix polymer and that of their composites with $10 \mathrm{vol} \%$ and $40 \mathrm{vol} \%$ filler content, respectively. Symbols: $(\diamond) \mathrm{PP} ;(\bigcirc)$ LDPE; $(\triangle) \mathrm{HDPE} ;(\nabla)$ PS; $(\triangleleft)$ PETG; $(\triangleright)$ PLA; empty symbols: SP20; full symbols: SPF. 


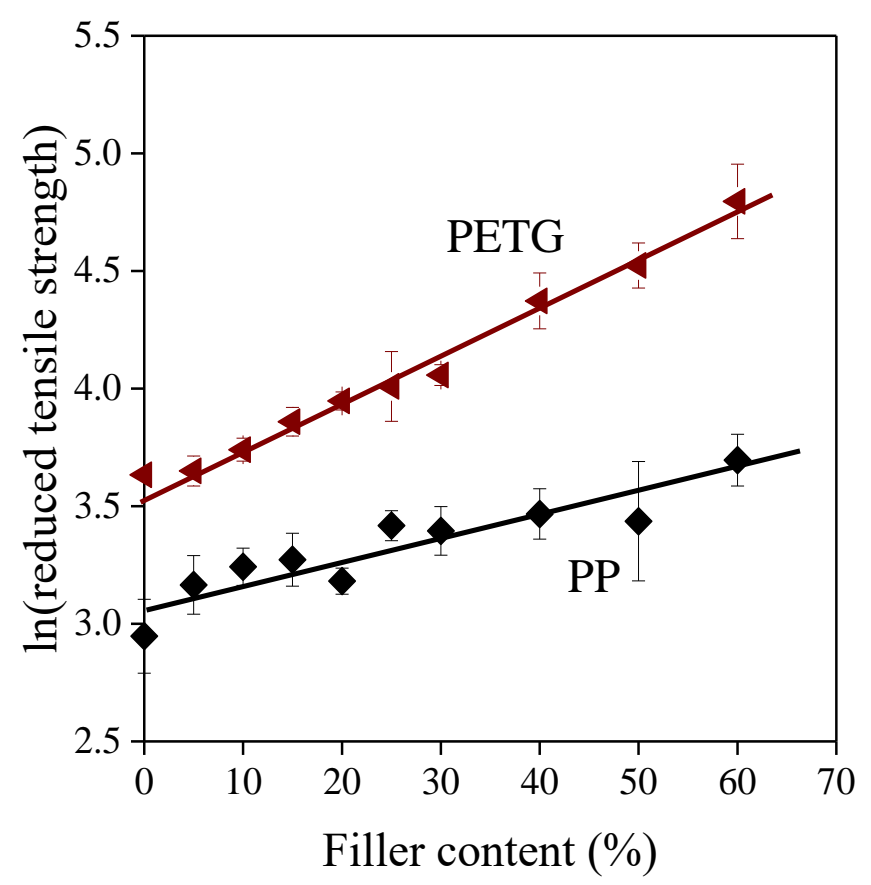

Figure 7. Reduced tensile strength of two composite series plotted against filler content in the form of Equation (7). Symbols: (४)) PP/SP20; (४)) PETG/SP20. Empty symbols represent data omitted from fitting.

Table 3. Reinforcing effect of sunflower hull in the polymers studied.

\begin{tabular}{|c|c|c|c|c|c|}
\hline $\begin{array}{l}\text { Matrix } \\
\text { Polymer }\end{array}$ & Filler & $\begin{array}{c}\text { True Tensile Strength of } \\
\text { Matrix Polymer, } \sigma_{T m}(\mathrm{MPa})\end{array}$ & $B$ & $\mathbf{R}^{2 \mathrm{a}}$ & $B \ln \sigma_{T m}$ \\
\hline \multirow{2}{*}{$\mathrm{PP}$} & SP20 & \multirow{2}{*}{$91.19 \pm 17.04$} & $0.83 \pm 0.14$ & 0.8339 & 3.75 \\
\hline & SPF & & $1.10 \pm 0.16$ & 0.8731 & 4.96 \\
\hline \multirow{2}{*}{ LDPE } & SP20 & \multirow{2}{*}{$43.56 \pm 4.08$} & $1.90 \pm 0.38$ & 0.8299 & 7.17 \\
\hline & SPF & & $1.68 \pm 0.21$ & 0.9274 & 6.34 \\
\hline \multirow{2}{*}{ HDPE } & SP20 & \multirow{2}{*}{$94.20 \pm 8.90$} & $1.39 \pm 0.07$ & 0.9882 & 6.32 \\
\hline & SPF & & $1.08 \pm 0.12$ & 0.9456 & 4.91 \\
\hline \multirow{2}{*}{ PS } & SP20 & \multirow{2}{*}{$18.13 \pm 0.78$} & $2.56 \pm 0.22$ & 0.9558 & 7.42 \\
\hline & SPF & & $2.65 \pm 0.13$ & 0.9847 & 7.68 \\
\hline \multirow{2}{*}{ PETG } & SP20 & \multirow{2}{*}{$37.83 \pm 2.54$} & $2.04 \pm 0.08$ & 0.9895 & 7.41 \\
\hline & SPF & & $2.57 \pm 0.13$ & 0.9834 & 9.34 \\
\hline \multirow{2}{*}{ PLA } & SP20 & \multirow{2}{*}{$52.88 \pm 3.40$} & $2.59 \pm 0.16$ & 0.9748 & 10.28 \\
\hline & SPF & & $2.50 \pm 0.11$ & 0.9877 & 9.92 \\
\hline
\end{tabular}

${ }^{a}$ Determination coefficient indicating the goodness of the fit.

According to Equation (6), there is a linear correlation between parameter $B$ and the logarithm of matrix strength, which is corroborated by Figure 8 . This implies that $B$ values contain not only the effect of interfacial adhesion but also that of matrix properties, and more reliable conclusions could be drawn from the $B$ values if they were made independent of the matrix properties. For this purpose, we used a correction proposed in our previous paper [71] to give a more accurate estimation of reinforcement, thus parameter $B$ was multiplied by the natural logarithm of the true tensile strength of the matrix polymer $\left(B \ln \sigma_{T m}\right)$. These values are also listed in Table 3, and, indeed, they show a slightly different picture of reinforcement. The lowest $B \ln \sigma_{T m}$ values, i.e., the smallest extent of reinforcement, still belong to the polyolefin based composites. The reinforcing effect of filler 
particles is increased somewhat in the PS matrix as $\pi$ electron interactions may develop in the interphase. If hydrogen bonds can develop between the components, the extent of reinforcement increases further. As a result, the reinforcing effect of the lignocellulosic fillers can be utilized mostly in PETG and PLA. This statement contradicts somewhat the considerable decreasing tendencies of strength for these two polymers (Figure 4). A possible explanation is that we can expect low inherent strength for the sunflower husk particles applied due to their disadvantageous geometrical factors [61].

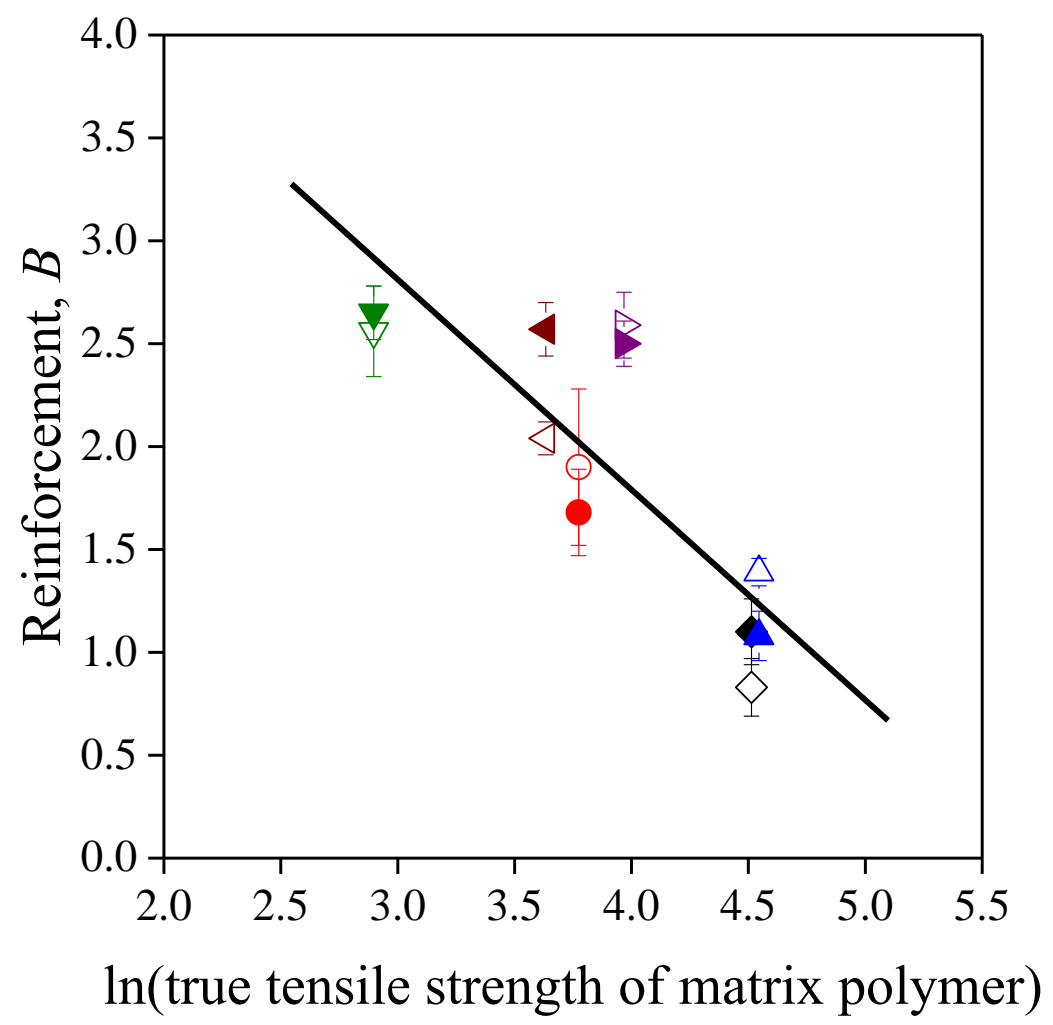

Figure 8. Correlation between reinforcement and matrix strength in the composites studied. Symbols: $(\diamond)$ PP; $(\bigcirc)$ LDPE; $(\triangle)$ HDPE; $(\nabla)$ PS; $(\triangleleft)$ PETG; $(\triangleright)$ PLA; empty symbols: SP20; full symbols: SPF.

\subsection{Effect of Adhesion and Structure on Reinforcement}

Another approach for the estimation of interfacial adhesion is the determination of the reversible work of adhesion. In this work, the reversible work of adhesion was calculated from the surface tension of the components. According to the theoretical assumptions of Fowkes [72], the surface free energy is the sum of contributions from the different intermolecular forces at the surface, thus the surface tension can be divided into a dispersion and a polar component. This latter includes also specific forces, such as $\pi$ electron interactions and hydrogen bonds. As a result, the reversible work of adhesion can be estimated also by the following formula [73]

$$
W_{m f}=2 \sqrt{\gamma_{m}^{d} \cdot \gamma_{f}^{d}}+2 \sqrt{\gamma_{m}^{p} \cdot \gamma_{f}^{p}}
$$

where $W_{m f}$ is the reversible work of adhesion between the matrix and the filler, $\gamma$ is the surface tension, the subscripts $m$ and $f$ represent the matrix and the filler, respectively, while the subscripts $d$ and $p$ denote the dispersion and polar component of surface tension, respectively. The dispersion and polar surface tension of sunflower husk was found to be $41.3 \mathrm{~mJ} / \mathrm{m}^{2}$ and $1.8 \mathrm{~mJ} / \mathrm{m}^{2}$, respectively, while the calculated $W_{m f}$ values with the measured $\gamma$ values of the polymers are collected in Table 4 . We can draw the same conclusions from these results as from the $B \ln \sigma_{T m}$ values shown in Table 3, and even the order of the data is the same. This observation is visualized by the linear correlation between them in Figure 9 . 
Table 4. The dispersion and polar surface tension components of the polymers used in the study, and the reversible work of adhesion in their composites.

\begin{tabular}{|c|c|c|c|}
\hline \multirow[b]{2}{*}{ Matrix Polymer } & \multicolumn{2}{|c|}{ Surface Tension $\left(\mathrm{mJ} / \mathrm{m}^{2}\right)$} & \multirow{2}{*}{$\begin{array}{c}\text { Reversible Work of } \\
\text { Adhesion, } W_{m f} \\
\left(\mathrm{~mJ} / \mathrm{m}^{2}\right)\end{array}$} \\
\hline & $\begin{array}{c}\text { Dispersion } \\
\text { Component, } \gamma_{s}{ }^{d}\end{array}$ & $\begin{array}{c}\text { Polar Component, } \\
\gamma_{s}{ }^{p}\end{array}$ & \\
\hline $\mathrm{PP}$ & 39.0 & 0.2 & 73.4 \\
\hline LDPE & 35.3 & 3.1 & 81.1 \\
\hline HDPE & 37.2 & 0.6 & 80.5 \\
\hline PS & 40.5 & 1.1 & 84.6 \\
\hline PETG & 43.7 & 2.7 & 89.3 \\
\hline PLA & 43.2 & 4.5 & 90.1 \\
\hline
\end{tabular}

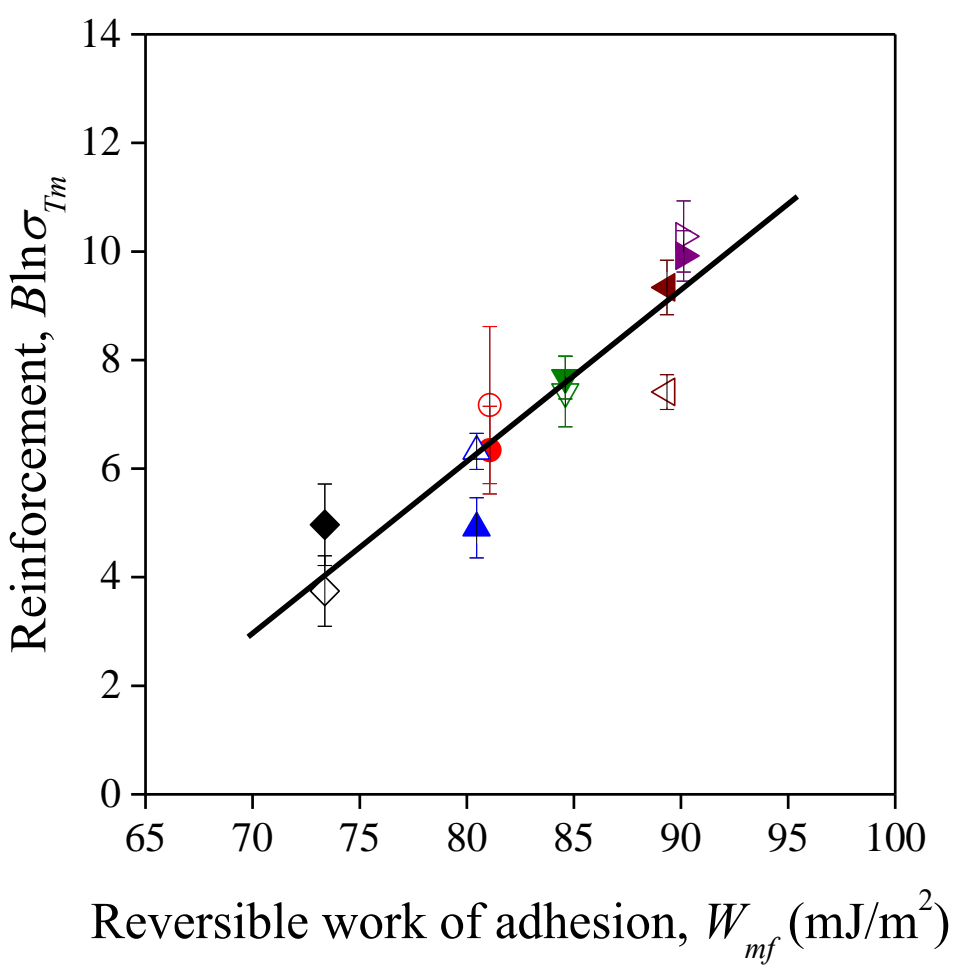

Figure 9. Correlation between reversible work of adhesion and reinforcement in the composites studied. Symbols: $(\diamond)$ PP; $(\bigcirc)$ LDPE; $(\triangle)$ HDPE; $(\nabla)$ PS; $(\triangleleft)$ PETG; $(\triangleright)$ PLA; empty symbols: SP20; full symbols: SPF.

The results of statistical analysis, namely ANCOVA, also corroborated the dominant role of adhesion in the determination of reinforcement. The effect of the reversible work of adhesion was statistically significant $(p=0.0028)$, while that of the filler type was not $(p=0.8912)$. Although the particle size was quite different in the two types of milled sunflower husk used in our experiments (1100 $\mu \mathrm{m}$ for SP20, and $2600 \mu \mathrm{m}$ for SPF), our previous results about lignocellulosic composites showed that the aspect ratio of a filler particle is a more relevant factor than particle size [62]. Therefore, the negligible effect of filler structure may be related to the similar aspect ratio of the lignocellulosic fillers (2.8 for SP20, and 3.3 for SPF).

\section{Conclusions}

In this paper, a comprehensive study is presented about the role of interfacial adhesion and structure in polymer/lignocellulose composites. The lignocellulosic filler was sunflower husk which is an agricultural waste available at low price and in large quantities. The modulus of the composites is limited by several factors. In polymer matrices with low surface energy, the debonding of matrix/filler interface around larger particles may occur 
even at very small deformations. In addition, at larger filler contents, sunflower husk particles physically contact each other resulting in very weak associations. Interfacial adhesion was estimated quantitatively from the extent of reinforcement and the reversible work of adhesion. Both approaches provided concordant results about interfacial interactions. Only weak van der Waals forces act in the interphase of polyolefin based composites, which results in poor adhesion and reinforcement. For the PS based systems, the reinforcing effect of sunflower husk particles is increased, which can be related to by the formation of $\pi$ electron interactions in the interphase. Among the polymers studied, interfacial adhesion is the strongest in the PLA and PETG based composites since hydrogen bonds can also develop in the interphase. Regarding filler structure, no difference was found between the reinforcing effects of the two types of milled sunflower husk used in our experiments, which can be explained by their similar aspect ratio. For all series, stiff and rigid composites are obtained at large sunflower husk loadings, which could be mitigated by the application of elastomers. The relatively low strength of the composites might be improved by increasing the inherent strength of sunflower husk particles. For this purpose, both the modification of filler geometry by further milling and the chemical treatment of the filler particles could be beneficial.

Author Contributions: Conceptualization, J.M. and D.K.; methodology, D.K.; microstructural analysis, Z.K.; investigation, Z.K.; writing—original draft preparation, D.K.; writing—review and editing, E.F., J.M. and D.K.; formal analysis, D.K.; methodology, D.K.; visualization, E.F. and J.M.; supervision, D.K. and J.M. All authors have read and agreed to the published version of the manuscript.

Funding: This research was funded by the National Research, Development and Innovation Fund of Hungary (OTKA Grant No. FK 129270).

Institutional Review Board Statement: Not applicable.

Informed Consent Statement: Not applicable.

Data Availability Statement: The data presented in this study are available on request from the corresponding author.

Conflicts of Interest: The authors declare no conflict of interest.

\section{References}

1. Siracusa, V.; Blanco, I. Bio-Polyethylene (Bio-PE), Bio-Polypropylene (Bio-PP) and Bio-Poly(ethylene terephthalate) (Bio-PET): Recent Developments in Bio-Based Polymers Analogous to Petroleum-Derived Ones for Packaging and Engineering Applications. Polymers 2020, 12, 1641. [CrossRef] [PubMed]

2. Brito, G.F.; Agrawal, P.; Araújo, E.M.; de Mélo, T.J.A. Polylactide/biopolyethylene bioblends. Polímeros 2012, $22,427-429$. [CrossRef]

3. Mancini, E.; Antonelli, M.G.; Zobel, P.B.; Sasso, M. Characterization and analytical parametrization of composite in cellulose fibre and PVA matrix. Compos. Part B Eng. 2019, 172, 496-505. [CrossRef]

4. Grylewicz, A.; Spychaj, T.; Zdanowicz, M. Thermoplastic starch/wood biocomposites processed with deep eutectic solvents. Compos. Part A Appl. Sci. Manuf. 2019, 121, 517-524. [CrossRef]

5. Olaiya, N.G.; Surya, I.; Oke, P.K.; Rizal, S.; Sadiku, E.R.; Ray, S.S.; Farayibi, P.K.; Hossain, M.S.; Khalil, H.P.S.A. Properties and characterization of a PLA-chitin-starch biodegradable polymer composite. Polymers 2019, 11, 1656. [CrossRef]

6. Móczó, J.; Kun, D.; Fekete, E. Desiccant effect of starch in polylactic acid composites. Express Polym. Lett. 2018, 12, 1014-1024. [CrossRef]

7. Singamneni, S.; Velu, R.; Behera, M.P.; Scott, S.; Brorens, P.; Harland, D.; Gerrard, J. Selective laser sintering responses of keratin-based bio-polymer composites. Mater. Des. 2019, 183, 108087. [CrossRef]

8. Chen, J.; Guo, J.; Zhao, M.; Zhang, R.; Guan, F. Hydrogen bonding in chitosan/Antarctic krill protein composite system: Study on construction and enhancement mechanism. Int. J. Biol. Macromol. 2020, 142, 513-520. [CrossRef]

9. Park, C.W.; Youe, W.J.; Namgung, H.W.; Han, S.Y.; Seo, P.N.; Chae, H.M.; Lee, S. Effect of lignocellulose nanofibril and polymeric methylene diphenyl diisocyanate addition on plasticized lignin/polycaprolactone composites. BioResources 2019, 13, 6802-6817.

10. Romhányi, V.; Kun, D.; Pukánszky, B. Correlations among Miscibility, Structure, and Properties in Thermoplastic Polymer/Lignin Blends. ACS Sustain. Chem. Eng. 2018, 6, 14323-14331. [CrossRef]

11. Bula, K.; Klapiszewski, Ł.; Jesionowski, T. Effect of processing conditions and functional silica/lignin content on the properties of bio-based composite thin sheet films. Polym. Test. 2019, 77, 105911. [CrossRef] 
12. Dias, O.A.T.; Sain, M.; Cesarino, I.; Leão, A.L. Development of high bio-content polypropylene composites with different industrial lignins. Polym. Adv. Technol. 2019, 30, 70-78. [CrossRef]

13. Abdelwahab, M.A.; Misra, M.; Mohanty, A.K. Injection molded biocomposites from polypropylene and lignin: Effect of compatibilizers on interfacial adhesion and performance. Ind. Crop. Prod. 2019, 132, 497-510. [CrossRef]

14. Muthuraj, R.; Hajee, M.; Horrocks, A.R.; Kandola, B.K. Biopolymer blends from hardwood lignin and bio-polyamides: Compatibility and miscibility. Int. J. Biol. Macromol. 2019, 132, 439-450. [CrossRef] [PubMed]

15. Nagy, S.; Csiszár, E.; Kun, D.; Koczka, B. Cellulose nanocrystal/amino-aldehyde biocomposite films. Carbohydr. Polym. 2018, 194, 51-60. [CrossRef]

16. De Andrade, M.R.; Nery, T.B.R.; e Santana, T.I.S.; Leal, I.L.; Rodrigues, L.A.P.; Reis, J.H.O.; Druzian, J.I.; Machado, B.A.S. Effect of cellulose nanocrystals from different lignocellulosic residues to chitosan/glycerol films. Polymers 2019, 11, 658. [CrossRef]

17. Rigotti, D.; Checchetto, R.; Tarter, S.; Caretti, D.; Rizzuto, M.; Fambri, L.; Pegoretti, A. Polylactic acid-lauryl functionalized nanocellulose nanocomposites: Microstructural, thermo-mechanical and gas transport properties. Express Polym. Lett. 2019, 13, 858-876. [CrossRef]

18. Montava-Jordà, S.; Torres-Giner, S.; Ferrandiz-Bou, S.; Quiles-Carrillo, L.; Montanes, N. Development of Sustainable and CostCompetitive Injection-Molded Pieces of Partially Bio-Based Polyethylene Terephthalate through the Valorization of Cotton Textile Waste. Int. J. Mol. Sci. 2019, 20, 1378. [CrossRef]

19. Panariello, L.; Coltelli, M.B.; Buchignani, M.; Lazzeri, A. Chitosan and nano-structured chitin for biobased anti-microbial treatments onto cellulose based materials. Eur. Polym. J. 2019, 113, 328-339. [CrossRef]

20. Idumah, C.I.; Hassan, A.; Bourbigot, S. Synergistic effect of exfoliated graphene nanoplatelets and non-halogen flame retardants on flame retardancy and thermal properties of kenaf flour-PP nanocomposites. J. Therm. Anal. Calorim. 2018, 134, 1681-1703. [CrossRef]

21. Kumar, A.; Tumu, V.R. Physicochemical properties of the electron beam irradiated bamboo powder and its bio-composites with PLA. Compos. Part B Eng. 2019, 175, 107098. [CrossRef]

22. Panaitescu, D.M.; Vuluga, Z.; Sanporean, C.G.; Nicolae, C.A.; Gabor, A.R.; Trusca, R. High flow polypropylene/SEBS composites reinforced with differently treated hemp fibers for injection molded parts. Compos. Part B Eng. 2019, 174, 107062. [CrossRef]

23. Várdai, R.; Lummerstorfer, T.; Pretschuh, C.; Jerabek, M.; Gahleitner, M.; Pukánszky, B.; Renner, K. Impact modification of PP/wood composites: A new approach using hybrid fibers. Express Polym. Lett. 2019, 13, 223-234. [CrossRef]

24. Bazan, P.; Mierzwiński, D.; Bogucki, R.; Kuciel, S. Bio-Based Polyethylene Composites with Natural Fiber: Mechanical, Thermal, and Ageing Properties. Materials 2020, 13, 2595. [CrossRef] [PubMed]

25. Muthuraj, R.; Lacoste, C.; Lacroix, P.; Bergeret, A. Sustainable thermal insulation biocomposites from rice husk, wheat husk, wood fibers and textile waste fibers: Elaboration and performances evaluation. Ind. Crop. Prod. 2019, 135, 238-245. [CrossRef]

26. Dong, S.; Yuan, F.; Yang, L.; Chi, S.; Zhong, J.; Lei, J.; Bao, L.; Wang, J. Clean and sustainable biocomposites based on supramolecular interactions induced thermoplasticization of wheat straw powders. J. Clean. Prod. 2019, 233, 590-600. [CrossRef]

27. Anggono, J.; Suwandi, S.; Rassy, A.; Hariyati, P.; Aria, W. Performance and evaluation of low cost sugarcane bagassePolypropylene biocomposites as candidate material for automotive parcel tray. Mater. Sci. Forum 2018, 923, 40-46. [CrossRef]

28. Chen, B.; Cai, D.; Luo, Z.; Chen, C.; Zhang, C.; Qin, P.; Cao, H.; Tan, T. Corncob residual reinforced polyethylene composites considering the biorefinery process and the enhancement of performance. J. Clean. Prod. 2018, 198, 452-462. [CrossRef]

29. Eschenhagen, A.; Raj, M.; Rodrigo, N.; Zamora, A.; Labonne, L.; Evon, P.; Welemane, H. Investigation of Miscanthus and Sunflower Stalk Fiber-Reinforced Composites for Insulation Applications. Adv. Civ. Eng. 2019, 2019, 9328087. [CrossRef]

30. Kamireddy, S.R.; Schaefer, C.; Defrese, M.; Degenstein, J.; Ji, Y. Pretreatment and enzymatic hydrolysis of sunflower hulls for fermentable sugar production. Int. J. Agric. Biol. Eng. 2012, 5, 62-70.

31. Seiler, G.J.; Gulya, T.J. Sunflower: Overview. In Reference Module in Food Science; Elsevier: Amsterdam, The Netherlands, 2016.

32. Angellier-Coussy, H.; Guillard, V.; Gastaldi, E.; Peyron, S.; Gontard, N. Lignocellulosic Composite Materials; Kalia, S., Ed.; Springer Series on Polymer and Composite Materials; Springer: Cham, Switzerland, 2018.

33. Grozdanov, A.; Avella, M.; Buzarovska, A.; Gentile, G.; Errico, M. Reuse of natural fiber reinforced eco-composites in polymer mortars. Polym. Eng. Sci. 2010, 50, 762-766. [CrossRef]

34. Meyer, S.; Meyer, U.; Trumme, R.; Simeone, C.; Albers, S. Process for Producing a Bioplastics Product. W.O. Patent 186,743, 2 November 2017.

35. Jacob, A. WPC industry focuses on performance and cost. Reinf. Plast. 2006, 50, 32-33. [CrossRef]

36. Suddell, B.C.; Evans, W.J. Natural fiber composites in automotive applications. In Natural Fibers, Biopolymers, and Biocomposites; Mohanty, A.K., Misra, M., Drzal, L.T., Eds.; CRC Press: Boca Raton, FL, USA, 2005; pp. 231-259.

37. Spear, M.J.; Eder, A.; Carus, M. 10-Wood polymer composites. In Wood Composites; Ansell, M.P., Ed.; Woodhead Publishing: Cambridge, UK, 2015; pp. 195-249.

38. Kun, D.; Pukánszky, B. Polymer/lignin blends: Interactions, properties, applications. Eur. Polym. J. 2017, 93, 618-641. [CrossRef]

39. Alam, M.A.; Sapuan, S.; Mansor, M. Design characteristics, codes and standards of natural fibre composites. In Advanced High Strength Natural Fibre Composites in Construction; Fan, M., Fu, F., Eds.; Elsevier: Amsterdam, The Netherlands, 2017; pp. 511-528.

40. Friedrich, D. An analytic algorithm-based method to assess the long term structural performance of wood-polymer composites. J. Build. Eng. 2018, 20,367-376. [CrossRef] 
41. Sui, G.; Fuqua, M.A.; Ulven, C.A.; Zhong, W.H. A plant fiber reinforced polymer composite prepared by a twin-screw extruder. Bioresource Technol. 2009, 100, 1246-1251. [CrossRef]

42. Salasinska, K.; Ryszkowska, J. The effect of filler chemical constitution and morphological properties on the mechanical properties of natural fiber composites. Compos. Interface 2015, 22, 39-50. [CrossRef]

43. Marhoon, I. Effect of sunflower husk particles added to polyurethane polymer matrix composite. Int. J. Sci. Technol. Res. 2017, 6 , 174-176.

44. Barczewski, M.; Matykiewicz, D.; Piasecki, A.; Szostak, M. Polyethylene green composites modified with post agricultural waste filler: Thermo-mechanical and damping properties. Compos. Interface 2018, 25, 287-299. [CrossRef]

45. Maldas, D.; Kokta, V. Interfacial adhesion of lignocellulosic materials in polymer composites: An overview. Compos. Interface 1993, 1, 87-108. [CrossRef]

46. Kárpáti, Z.; Kun, D.; Fekete, E.; Móczó, J. Structural biomaterials engineered from lignocellulosic agricultural waste. J. Appl. Polym. Sci. 2021, 138, 50617. [CrossRef]

47. Owens, D.K.; Wendt, R.C. Estimation of the surface free energy of polymers. J. Appl. Polym. Sci. 1969, 13, 1741-1747. [CrossRef]

48. Rabel, W. Einige Aspekte der Benetzungstheorie und ihre Anwendung auf die Untersuchung und Veränderung der Oberflächeneigenschaften von Polymeren. Farbe Lack 1971, 77, 997-1005.

49. Kaelble, D.H.; Uy, K.C. A reinterpretation of organic liquid-polytetrafluoroethylene surface interactions. J. Adhes. 1970, 2, 50-60. [CrossRef]

50. Kaelble, D.H. Dispersion-Polar Surface Tension Properties of Organic Solids. J. Adhes. 1970, 2, 66-81. [CrossRef]

51. Lewis, T.B.; Nielsen, L.E. Dynamic mechanical properties of particulate-filled composites. J. Appl. Polym. Sci. 1970, 14, 1449-1471. [CrossRef]

52. Móczó, J.; Pukánszky, B. Particulate Fillers in Thermoplastics. In Fillers for Polymer Applications; Polymers and Polymeric Composites: A Reference Series; Rothon, R., Ed.; Springer: Cham, Switzerland, 2017. [CrossRef]

53. Donev, A.; Cisse, I.; Sachs, D.; Variano, E.A.; Stillinger, F.H.; Connelly, R.; Torquato, S.; Chaikin, P.M. Improving the Density of Jammed Disordered Packings Using Ellipsoids. Science 2004, 303, 990-993. [CrossRef]

54. Kronbergs, E. Mechanical strength testing of stalk materials and compacting energy evaluation. Ind. Crop. Prod. 2000, 11, 211-216. [CrossRef]

55. Young, R.A. Vegetable Fibers. In Encyclopedia of Polymer Science and Technology, 3rd ed.; Part 3; Mark, H.F., Ed.; Wiley: New York, NY, USA, 2004; Volume 12.

56. Avérous, L.; Le Digabel, F. Properties of biocomposites based on lignocellulosic fillers. Carbohydr. Polym. 2006, 66, 480-493. [CrossRef]

57. Dányádi, L.; Renner, K.; Szabó, Z.; Nagy, G.; Móczó, J.; Pukánszky, B. Wood flour filled PP composites: Adhesion, deformation, failure. Polym. Adv. Technol. 2006, 17, 967-974. [CrossRef]

58. Anggono, J.; Farkas, Á.E.; Bartos, A.; Móczó, J.; Purwaningsih, H.; Pukánszky, B. Deformation and failure of sugarcane bagasse reinforced PP. Eur. Polym. J. 2019, 112, 153-160. [CrossRef]

59. Dányádi, L.; Renner, K.; Móczó, J.; Pukánszky, B. Wood flour filled polypropylene composites: Interfacial adhesion and micromechanical deformations. Polym. Eng. Sci. 2007, 47, 1246-1255. [CrossRef]

60. Renner, K.; Móczó, J.; Suba, P.; Pukánszky, B. Micromechanical deformations in PP/lignocellulosic filler composites: Effect of matrix properties. Compos. Sci. Technol. 2010, 70, 1141-1147. [CrossRef]

61. Renner, K.; Móczó, J.; Pukánszky, B. Deformation and failure of PP composites reinforced with lignocellulosic fibers: Effect of inherent strength of the particles. Compos. Sci. Technol. 2009, 69, 1653-1659. [CrossRef]

62. Faludi, G.; Dora, G.; Imre, B.; Renner, K.; Móczó, J.; Pukánszky, B. PLA/lignocellulosic fiber composites: Particle characteristics, interfacial adhesion, and failure mechanism. J. Appl. Polym. Sci. 2014, 131, 39902. [CrossRef]

63. Pukánszky, B. Influence of interface interaction on the ultimate tensile properties of polymer composites. Composites 1990, 21, 255-262. [CrossRef]

64. Nicolais, L.; Narkis, M. Stress-strain behavior of styrene-acrylonitrile/glass bead composites in the glassy region. Polym. Eng. Sci. 1971, 11, 194-199. [CrossRef]

65. Turcsányi, B.; Pukánszky, B.; Tüdős, F. Effect on Interfacial Interaction on the Tensile Yield Stress of Polymer Composites. In Interfaces in Polymer, Ceramic, and Metal Matrix Composites; Ishida, H., Ed.; Elsevier: New York, NY, USA, 1988 ; pp. $467-477$.

66. Jang, L.W.; Lee, D.C. Polystyrene/bisphenol A polycarbonate molecular composite by in situ polymerization. I. Preparation and characterization. Polymer 2000, 41, 1749-1756. [CrossRef]

67. Zhao, D.; Zhu, G.; Ding, Y.; Zheng, J. Construction of a Different Polymer Chain Structure to Study $\pi-\pi$ Interaction between Polymer and Reduced Graphene Oxide. Polymers 2018, 10, 716. [CrossRef]

68. Tardio, S.; Abel, M.-L.; Carr, R.H.; Watts, J.F. Polystyrene-silicon bonding through $\pi$ electrons: A combined XPS and DFT study. Surf. Interface Anal. 2016, 48, 556-560. [CrossRef]

69. Shen, B.; Zhai, W.; Chen, C.; Lu, D.; Wang, J.; Zheng, W. Melt Blending In situ Enhances the Interaction between Polystyrene and Graphene through $\pi-\pi$ Stacking. ACS Appl. Mater. Interfaces 2011, 3, 3103-3109. [CrossRef]

70. Müller, P.; Bere, J.; Fekete, E.; Móczó, J.; Nagy, B.; Kállay, M.; Gyarmati, B.; Pukánszky, B. Interactions, structure and properties in PLA/plasticized starch blends. Polymer 2016, 103, 9-18. [CrossRef] 
71. Kajtár, D.A.; Kenyó, C.; Renner, K.; Móczó, J.; Fekete, E.; Kröhnke, C.; Pukanszky, B. Interfacial interactions and reinforcement in thermoplastics/zeolite composites. Compos. Part B Eng. 2017, 114, 386-394. [CrossRef]

72. Fowkes, F.M. Determination of interfacial tensions, contact angles, and dispersion forces in surfaces by assuming additivity of intermolecular interactions in surfaces. J. Phys. Chem. 1962, 66, 382. [CrossRef]

73. Huntsberger, J.R. Adhesion of Plasticized Poly(vinyl Butyral) to Glass. J. Adhes. 1981, 13, 107-129. [CrossRef] 